RAD Conference Proceedings, vol. 3, pp. 77-80, 2018

ISSN 2466-4626 (online) | DOI: 10.21175/RadProc.2018.16

www.rad-proceedings.org

\title{
ANALYSIS OF ACTIVITY CONCENTRATION OF NATURAL RADIONUCLIDES IN THE SOIL OF THE INSTITUTE OF APPLIED NUCLEAR PHYSICS IN ALBANIA AND THE ASSESSMENT OF ANNUAL EFFECTIVE DOSE
}

\author{
Manjola Shyti ${ }^{*}$, Irma Bërdufi ${ }^{1}$, Florinda Cfarku' ${ }^{1}$, Gerti Xhixha² \\ ${ }^{1}$ Institute of Applied Nuclear Physics, University of Tirana, Tirana, Albania \\ ${ }^{2}$ Department of Physics, Faculty of Natural Sciences, University of Tirana, Tirana, Albania
}

\begin{abstract}
Terrestrial gamma radiation levels are significantly affected by the radionuclides that are present in the soil, which in turn can be used for the assessment of the terrestrial gamma dose rate. This study is important because the employees of this institute, in addition to professional exposure, will be familiar with the average annual effective dose equivalents (AEDEs) in soils that come from this area. The main radioactive materials are the long-lived radionuclides, such as ${ }^{238} \mathrm{U}$, ${ }^{232}$ Th and ${ }^{40} \mathrm{~K}$, known as NORMs (Naturally Occurring Radionuclide Materials). Natural radioactivity analysis has been done for the soil samples collected from the area of the Institute of Applied Nuclear Physics (IANP) in Tirana, Albania. The activity concentration of Radium $\left({ }^{226} \mathrm{Ra}\right)$, Thorium $\left({ }^{232} \mathrm{Th}\right)$ and Potassium $\left({ }^{\circ} \mathrm{K}\right)$ were measured in these samples using HPGe (High Purity Germanium) detector based on low background gamma-ray counting system. From the measured activity concentration of the above three natural radionuclides, the external gamma absorbed dose rate and the annual effective dose were calculated. The obtained mean values of gamma absorbed dose rate and annual effective dose in soil samples were found to be comparable with the worldwide average as reported by United Nations Scientific Committee on the Effects of Atomic Radiation. The natural radioactivity levels in soils of IANP area had never been studied before. This study aims to determine the dose rate in order to assess the health risks from the activity concentration of the natural radionuclides as ${ }^{238} U,{ }^{232} T h$ and ${ }^{40} \mathrm{~K}$ in the soil. Also, the Radium equivalent $\left(R a_{e q}\right)$ of the samples is calculated and compared with the similar data reported in literature. The values of the outdoor annual effective dose were in the range of 0.02 to $0.11 \mathrm{mSv}$, showing that the area of IANP was radiologically safe.
\end{abstract}

Key words: Natural radioactivity, HPGe detector, activity concentration, annual effective dose

\section{INTRODUCTION}

Human beings have always been exposed to natural radiations arising from within and outside the earth. The main radioactive materials are long-lived radionuclides such as ${ }^{238} \mathrm{U},{ }^{232} \mathrm{Th}$, and ${ }^{40} \mathrm{~K}$, known as NORMs (Naturally Occurring Radionuclide Materials). Gamma radiation emitted from primordial radionuclides and their progeny is one of the main external sources of radiation exposure to humans [1].

Terrestrial radioactivity and the associated external exposure due to gamma radiation depend primarily on the geological formation and the soil type of the location; and these factors (geology and soil type) greatly influence the dose distribution from natural terrestrial radiation [2]. Total radiation dose to the world population has shown that approximately 86 percentage of the radiation to which humans are exposed is from natural radioactivity and the remaining 14 percentage is from anthropogenic radioactivity according to the UNSCEAR report (UNSCEAR, 2000) [3].
Since natural radiation is the largest contributor of external dose to the world population, the assessment of gamma radiation dose from natural sources is of particular importance [4]. Therefore, measurements of natural radioactivity in soil are of a great interest to many researchers throughout the world, which promoted worldwide national surveys in the last two decades.

We are working in collection of soil samples in different cities in Albania including here the city of Tirana and the area of IANP in order to produce a radiation map and to evaluate the public exposure.

To evaluate the terrestrial gamma-dose rate for outdoor occupations, it is very important to estimate the natural radioactivity level in soils. The natural radioactivity levels in soils of Institute of Applied Nuclear Physics (IANP) area in Tirana, Albania had never been studied before.

This study aims to determine the activity concentration of natural radionuclides such as ${ }^{238} \mathrm{U}$, ${ }^{232} \mathrm{Th}$ and ${ }^{4} \mathrm{~K}$ in the soil samples of IANP area, as well as the dose rate in order to assess the health risks. Also,

*manjolashyti@yahoo.com 
the data obtained from the measured samples are compared with similar data reported in literature.

\section{MATERIALS AND METHODS}

\subsection{Sampling and sample preparation}

At the Institute of Applied Nuclear Physics (IANP) area, which is located in the Tirana city (Fig.1), ten soil samples were collected from different points. In this study the samples were taken from the upper $10 \mathrm{~cm}$ layer of soil and were packed in labelled polythene bags. The locations of the samples were recorded with a global positioning system. In the laboratory, the samples were first dried at $105^{\circ} \mathrm{C}$ overnight for $24 \mathrm{~h}$, cleared of stones and pebbles, crushed and ground to a fine powder, homogenized, weighted and packed in standard $500 \mathrm{~mL}$ Marinelli beakers. The Marinelli beakers are sealed (for at least 4 weeks) with PVC tape and carefully labelled to allow the radon gas in the soil to reach equilibrium.

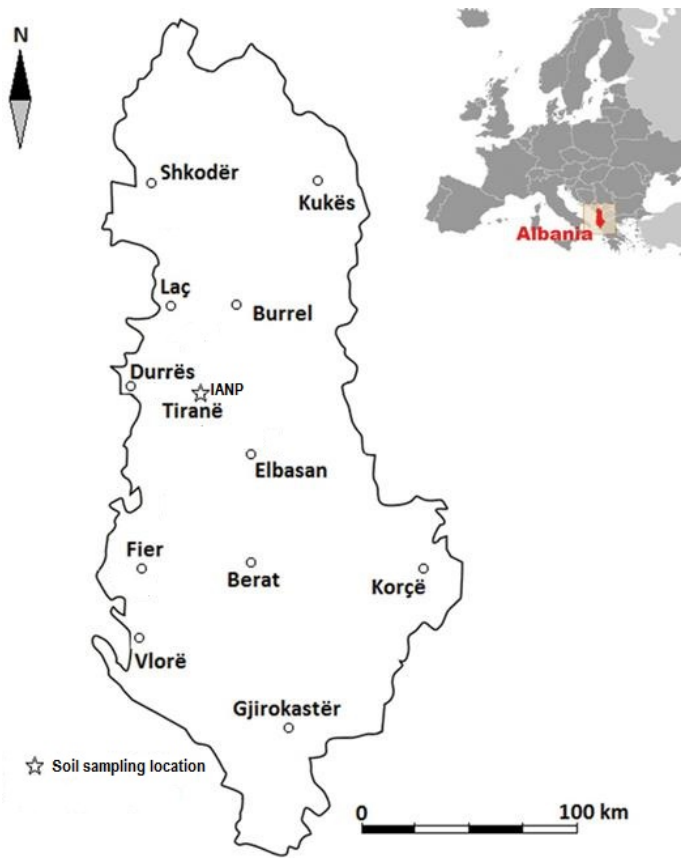

Figure 1. Simple map of Albania cities and the IANP soil sampling location

\subsection{High-resolution gamma-ray spectrometry measurements}

The radioactivities of the prepared samples were measured using a high-resolution gamma-ray spectrometry system with a coaxial high purity germanium detector with a relative efficiency of $40 \%$, and a resolution of $1.8 \mathrm{keV}$ for the $1332 \mathrm{keV}$ gamma ray emission of ${ }^{6} \mathrm{Co}$. The HPGe $\gamma$-ray detector (GC4018$7500 \mathrm{SL}$ ) is a Broad Energy Ge (BEGe) detector equipped with a composite carbon window and coupled with a digital spectrum analyzer, DSA-1000. The detector was well-shielded to minimize the $\gamma$-ray background to be able to measure low radioactivity.
For the analysis of spectra, Genie 2000 (VI.3.2.1) software from Canberra was used. Counting time interval was 86400 seconds for each sample. Energy was calibrated using different point sources, whereas efficiency was calibrated using a $500 \mathrm{~mL}$ multi-nuclide standard solution of: ${ }^{241} \mathrm{Am},{ }^{109} \mathrm{Cd},{ }^{139} \mathrm{Ce},{ }^{57} \mathrm{Co},{ }^{60} \mathrm{Co}$,

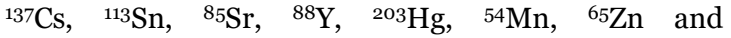
interpolated in the energy range of $60 \mathrm{keV}$ to 2000 $\mathrm{keV}$.

The combined uncertainty in the intrinsic detector efficiency calibration combining Type $\mathrm{A}$ and $\mathrm{B}$ uncertainties was found to be less than $10 \%$. The uncertainty in the full energy peak count rate which is determined by Type A evaluation will influence the precision of the fit, whereas uncertainties estimated using Type B evaluations will not.

The uncertainties in calibration source activity, gamma-energy intensities, linear attenuation coefficients and source-to-detector distance are all obtained using Type B evaluations.

The activity of ${ }^{226} \mathrm{Ra}$ was determined based on gamma ray emissions of ${ }^{214} \mathrm{~Pb}(295.21$ and $352 \mathrm{keV})$ and ${ }^{214} \mathrm{Bi}(609$ and $1120.29 \mathrm{keV}),{ }^{232} \mathrm{Th}$ was determined based on the emissions of ${ }^{228} \mathrm{Ac}$ (911.07 and $968.9 \mathrm{keV}$ ) and that of ${ }^{\circ} \mathrm{K}$ was determined from the emission at $1461.8 \mathrm{keV}$. The Minimum Detectable Activity (MDA) of ${ }^{238} \mathrm{U}\left({ }^{226} \mathrm{Ra}\right),{ }^{232} \mathrm{Th}$ and ${ }^{40} \mathrm{~K}$, calculated according to Currie formula [5], was $0.6 \mathrm{~Bq} \mathrm{~kg}^{-1}, 0.4 \mathrm{~Bq} \mathrm{~kg}^{-1}$ and 13 $\mathrm{Bq} \mathrm{kg-1}$.

\section{RESULTS AND DISCUSSION}

\subsection{Activity concentrations}

The activity concentrations of ${ }^{226} \mathrm{Ra}{ }^{232} \mathrm{Th}$ and ${ }^{40} \mathrm{~K}$ are reported in Table 1 . The average activity concentrations of ${ }^{238} \mathrm{U}\left({ }^{226} \mathrm{Ra}\right),{ }^{232} \mathrm{Th}$ and ${ }^{40} \mathrm{~K}$, were respectively $26.2 \pm 1.1 \mathrm{~Bq} \mathrm{~kg}^{-1}, 25.2 \pm 1.5 \mathrm{~Bq} \mathrm{~kg}^{-1}$ and $408.2 \pm 5.1 \mathrm{~Bq} \mathrm{~kg}^{-1}$ in the soil samples. The activity concentrations of ${ }^{\circ} \mathrm{K},{ }^{226} \mathrm{Ra}$ and ${ }^{232} \mathrm{Th}$ in the soil were found to be lower or comparable within $1 \sigma$ to the typical average activity concentrations in world, which are respectively $420 \mathrm{~Bq} \mathrm{~kg}^{-1}, 33 \mathrm{~Bq} \mathrm{~kg}^{-1}$ and $45 \mathrm{~Bq} \mathrm{~kg}^{-1}$. In Table 2 and Figure 1, what is shown is the level of natural radioactivity in IANP soil compared with those in other countries as given in UNSCEAR (2000). There is a normal distribution of activity concentration in representative samples. No regular trend in the variation of radioactivity has been observed.

Table 1. Activity concentrations of ${ }^{40} \mathrm{~K},{ }^{238} \mathrm{U}\left({ }^{226} \mathrm{Ra}\right)$ and ${ }^{232} \mathrm{Th}$ in the soil sample

\begin{tabular}{|c|c|c|c|c|c|c|}
\hline ID & $\begin{array}{c}{ }^{40} \mathrm{~K} \\
(\mathrm{~Bq} / \mathrm{kg})\end{array}$ & $\begin{array}{c}\sigma^{40} \\
\mathrm{~K} \\
(\mathrm{~Bq} / \mathrm{kg})\end{array}$ & $\begin{array}{c}{ }^{238} \mathrm{U} \\
(\mathrm{Bq} / \mathrm{Kg})\end{array}$ & $\begin{array}{c}\sigma \\
{ }^{238} \mathrm{U} \\
(\mathrm{Bq} / \mathrm{kg})\end{array}$ & $\begin{array}{c}{ }^{232} \mathrm{Th} \\
(\mathrm{Bq} / \mathrm{Kg})\end{array}$ & $\begin{array}{c}\sigma \\
{ }^{232} \mathrm{Th} \\
(\mathrm{Bq} / \mathrm{kg})\end{array}$ \\
\hline IANP 1 & 332.6 & 16.6 & 22.4 & 1.6 & 27.8 & 2.2 \\
\hline IANP 2 & 504.9 & 25.2 & 28.3 & 1.7 & 36.2 & 2.9 \\
\hline IANP 3 & 473.6 & 0.2 & 33.7 & 1.5 & 31.1 & 1.6 \\
\hline IANP 4 & 466.2 & 0.2 & 27.5 & 0.6 & 30.1 & 1.6 \\
\hline IANP 5 & 410.7 & 0.2 & 22.3 & 0.7 & 17.8 & 1.0 \\
\hline IANP 6 & 518.0 & 0.3 & 56.6 & 1.6 & 72.8 & 3.1 \\
\hline IANP 7 & 140.6 & 7.3 & 9.0 & 0.4 & 6.5 & 0.8 \\
\hline IANP 8 & 407.0 & 0.2 & 31.0 & 0.7 & 25.8 & 1.8 \\
\hline IANP 9 & 414.4 & 0.2 & 28.8 & 1.4 & 1.7 & 0.1 \\
\hline IANP 10 & 414.4 & 0.2 & 2.24 & 1.1 & 1.9 & 0.1 \\
\hline Average & $\mathbf{4 0 8 . 2}$ & $\mathbf{5 . 1}$ & $\mathbf{2 6 . 2}$ & $\mathbf{1 . 1}$ & $\mathbf{2 5 . 2}$ & $\mathbf{1 . 5}$ \\
\hline
\end{tabular}


M. Shyti et al., Assessment of annual effective dose at IANP, RAD Conf. Proc., vol. 3, 2018, 77-80

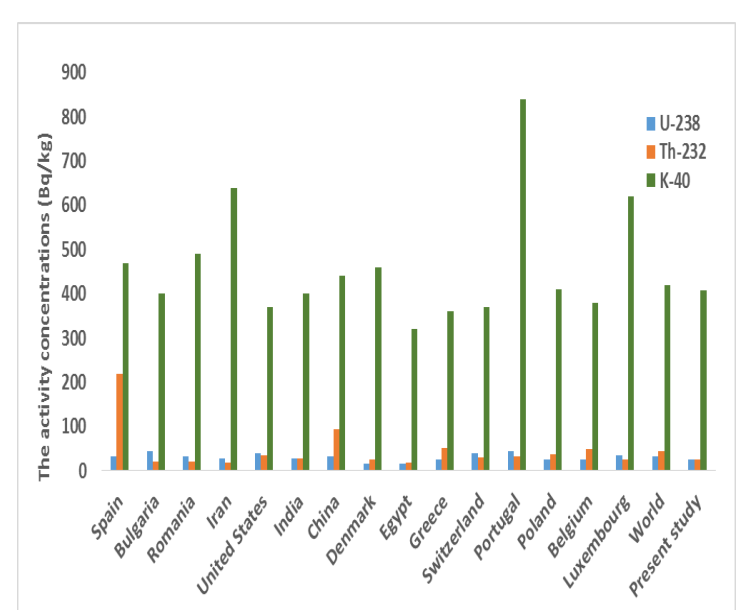

Figure 2. Comparison of natural radioactivity levels in IANP soil with those in others countries

3.2. Outdoor absorbed gamma dose rate and corresponding annual effective dose

Table 2. Comparison of natural radioactivity levels in IANP soil with those in others countries as given in UNSCEAR (2000)

\begin{tabular}{|c|c|c|c|c|c|c|}
\hline \multicolumn{7}{|c|}{ Concentration in soil (Bq/kg) } \\
\hline \multirow{2}{*}{ Country } & \multicolumn{2}{|c|}{$\mathbf{2 3}^{\mathbf{8}} \mathbf{U}$} & \multicolumn{2}{c|}{${ }^{\mathbf{2 3 2} \mathbf{T h}}$} & \multicolumn{2}{|c|}{$\mathbf{4 0}^{\mathbf{K}}$} \\
\cline { 2 - 7 } & Mean & Range & Mean & Range & Mean & Range \\
\hline Spain & 32 & $6-250$ & 221 & $35-125$ & 470 & $25-1650$ \\
\hline Bulgaria & 45 & $12-210$ & 21 & $4-77$ & 400 & $40-800$ \\
\hline Romania & 32 & $8-60$ & 21 & $1-190$ & 490 & $250-1100$ \\
\hline Iran & 28 & $8-55$ & 19 & $8-30$ & 640 & $250-980$ \\
\hline United States & 40 & $8-160$ & 35 & $4-130$ & 370 & $100-700$ \\
\hline India & 29 & $7-81$ & 28 & $22-88$ & 400 & $38-760$ \\
\hline China & 32 & $2-440$ & 95 & $16-200$ & 440 & $9-1800$ \\
\hline Denmark & 17 & $9-29$ & 27 & $5-50$ & 460 & $240-610$ \\
\hline Egypt & 17 & $5-64$ & 18 & $2-96$ & 320 & $29-650$ \\
\hline Greece & 25 & $1-240$ & 51 & $\mathbf{2 2 - 1 0 0}$ & 360 & $12-1570$ \\
\hline Switzerland & 40 & $10-900$ & 30 & $7-160$ & 370 & $40-1000$ \\
\hline Portugal & 44 & $8-65$ & 33 & $2-210$ & 840 & $\mathbf{2 2 0 - 1 2 3 0}$ \\
\hline Poland & 26 & $5-120$ & 38 & $11-75$ & 410 & $110-970$ \\
\hline Belgium & 26 & $5-50$ & 50 & $7-70$ & 380 & $70-900$ \\
\hline Luxembourg & 35 & $6-52$ & 25 & $4-70$ & 620 & $80-1800$ \\
\hline World & 33 & - & 45 & - & 420 & - \\
\hline Present & $\mathbf{2 6}$ & $\mathbf{2 - 5 7}$ & $\mathbf{2 5}$ & $\mathbf{2 - 7 3}$ & $\mathbf{4 0 8}$ & $\mathbf{1 4 1 - 5 1 8}$ \\
\hline study & & & & & \\
\hline
\end{tabular}

The external gamma dose rate in outdoor air can be evaluated from the activity concentrations of the ${ }^{238} \mathrm{U}$, ${ }^{232} \mathrm{Th}$ and ${ }^{40} \mathrm{~K}$ measured in soil samples. For natural gamma sources uniformly distributed in the ground, the outdoor absorbed gamma dose rate in air at a height of $1 \mathrm{~m}$ above the ground surface can be calculated by using the following formula [6]:

DRout $(n G y / h)=0.462 \cdot A_{R a}+0.604 \cdot A_{T h}+0.0417 \bullet A_{K}$

where $\mathrm{C}_{\mathrm{Ra}}, \mathrm{C}_{\mathrm{Th}}$ and $\mathrm{C}_{\mathrm{K}}$ are the activity concentrations of ${ }^{226} \mathrm{Ra},{ }^{232} \mathrm{Th}$ and ${ }^{40} \mathrm{~K}$ in $\mathrm{Bq} \mathrm{kg}{ }^{-1}$, respectively. 
M. Shyti et al., Assessment of annual effective dose at IANP, RAD Conf. Proc., vol. 3, 2018, 77-80

2. Beir VII Phase 2: Health risks from exposure to low levels of ionizing radiation Washington, Rep. 11340, National Academy of Sciences, Washington (DC), USA, 2006.

Retrieved from: http://www.philrutherford.com/R adiation Risk/BEIR/BEIR VII.pdf;

Retrieved on: Aug. 17, 2018

3. Sources and Effects of Ionizing Radiation, UNSCEAR Report (A/55/46), UNSCEAR, New York (NY), USA, 2000.

Retrieved from:

http://www.unscear.org/docs/publications/2000/ UNSCEAR 2000 Report Vol.I.pdf;

Retrieved on: Aug. 17, 2018

4. Sources, Effects and Risks of Ionizing Radiation, UNSCEAR Report (A/43/45), UNSCEAR, New York (NY), USA, 1988.
Retrieved from: http://www.unscear.org/docs/publ ications/1988/UNSCEAR 1988 Report.pdf;

Retrieved on: Aug. 17, 2018

5. L. A. Currie, "Limits for Qualitative Detection and Quantitative Determination Application to Radiochemistry," Anal. Chem., vol. 40, no. 3, pp. 586 - 593, Mar. 1986.

DOI: 10.1021/ac60259a007

6. S. Turhan, A. Köse, A. Varinlioğlu, İ. H. Arıkan, F Oğuz, B. Yücel, T. Özdemir, "Distribution of terrestrial and anthropogenic radionuclides in Turkish surface soil samples," Geoderma, vol. 187-188, pp. 117 - 124, Oct. 2012. DOI: 10.1016/j.geoderma.2012.04.017 